\title{
AVALIAÇÃO POR CÂMERA TERMOGRÁFICA DE IMPLANTE DE CO- POLIAMIDA ASSOCIADO A ELASTÔMERO TERMOPLÁSTICO EM TRAQUEIA DE COELHO ${ }^{1}$
}

\author{
Isabella Fernanda Bernardo Bini² \\ Laise Michi Yamashiro ${ }^{2}$ \\ Cléber Kazuo Ido ${ }^{2}$ \\ Juliana de Oliveira Ribeiro ${ }^{2}$ \\ Gabriel Luiz Montanhim² \\ Josiane Morais Pazzini ${ }^{3}$ \\ Thiago André Savitti de Sá Rocha ${ }^{4}$ \\ Luis Gustavo Gosuen Gonçalves Dias ${ }^{2}$ \\ Paola Castro Moraes ${ }^{2}$
}

\section{RESUMO}

A termografia é eficiente para detecção da temperatura da superfície corporal e pode ser utilizada como método auxiliar de diagnóstico de processos inflamatórios e na avaliação de padrões cicatriciais, o que permite sua ampla utilização na Medicina Veterinária. $\mathrm{O}$ procedimento tem ganhado destaque, pois trata-se de técnica não invasiva, indolor, de baixo custo e segura, pois dispensa a necessidade do uso de contrastes, sedação e radiação. $\mathrm{O}$ objetivo desse artigo é analisar a eficiência do uso da termografia na avaliação da biocompatibilidade em reparação tecidual traqueal, bem como identificar processos inflamatórios após a implantação da prótese impressa em impressão $3 \mathrm{D}$ de náilon associado ao elastômero termoplástico- PCTPE. Quinze coelhos machos, da linhagem Nova Zelândia Branco (Oryctolagus cuniculus), foram distribuídos em três grupos de períodos de avaliação diferentes (sete, 15 e 30 dias). As próteses tridimensionais foram implantadas após ressecção completa de três anéis traqueais. A avaliação das imagens termográficas foi efetuada no local de implantação da prótese traqueal no momento anterior ao procedimento cirúrgico e imediatamente antes da eutanásia. Houve diferença significativa entre os grupos, sendo que aos 30 dias a temperatura mínima $(p=0,0357)$, média $(p=0,0135)$ e máxima $(p=0,0058)$ foi menor quando comparado com os demais grupos. Isso justifica-se devido ao fato desse grupo se enquadrar na fase de maturação da reparação da ferida, onde não há mais inflamação ou formação de tecido de granulação, o que faz com que as temperaturas assumam valores mais baixos. Concluiu-se então a eficácia da técnica na detecção de padrões inflamatórios e cicatriciais.

Palavras-chave: biopolímeros; impressão 3D; prótese; reconstrução de traqueia; termografia.

\footnotetext{
${ }^{1}$ Fundação de Amparo à Pesquisa do Estado de São Paulo (FAPESP)

${ }^{2}$ Universidade Estadual Paulista "Júlio de Mesquita Filho"- Câmpus de Jaboticabal *Contato para correspondência. isa-bella-fbb@hotmail.com

${ }^{3}$ UNILAGO josipazzini@hotmail.com

${ }^{4}$ UNIVERSIDADE BRASIL vetcraft3d@gmail.com
}

Bini IFB, Yamashiro LM, Ido CK, Ribeiro JO, Montanhim GL, Pazzini JM, et al. Avaliação por câmera termográfica de implante de co-poliamida associado a elastômero termoplástico em traqueia de coelho. Vet. e Zootec. 2021; v28: 001-011. 


\title{
EVALUATION OF CO-POLYAMIDE IMPLANT COMPRISING A THERMOPLASTIC ELASTOMER IN RABBIT TRACHEA USING THERMOGRAPHIC CAMERA
}

\begin{abstract}
Thermography is efficient for detecting body surface temperature and can be used as an auxiliary method for the diagnosis of inflammatory processes and in the evaluation of scarring patterns, which allows its wide use in Veterinary Medicine. The procedure has gained prominence, as it is a non-invasive, painless, low-cost and safe technique, since it does not require the use of contrasts, sedation and radiation. The objective of this article is to analyze the efficiency of the use of thermography in the evaluation of biocompatibility in tracheal tissue repair, as well as to identify inflammatory processes after implantation of the 3D printed impression prosthesis of nylon associated with the thermoplastic elastomer - PCTPE. Fifteen male New Zealand White rabbits (Oryctolagus cuniculus) were divided into three groups of different evaluation periods (seven, 15 and 30 days). Three-dimensional prostheses were implanted after complete resection of three tracheal rings. The evaluation of the thermographic images was performed at the place of implantation of the tracheal prosthesis just before the surgical procedure and immediately before euthanasia. There was a significant difference between the groups, and at 30 days the minimum $(p=0,0357)$, average $(p=$ $0,0135)$ and maximum $(p=0,0058)$ temperature was lower when compared with the other groups. This is justified due to the fact that this group fits into the maturation phase of wound repair, where there is no more inflammation or formation of granulation tissue, which causes temperatures to assume lower values. It was concluded that the technique was effective in detecting inflammatory and scarring patterns.
\end{abstract}

Keywords: Biopolymers; 3D printing; prosthesis; tracheal reconstruction; thermography.

\section{EVALUACIÓN CON CÁMARA TERMOGRÁFICA DE UN IMPLANTE DE COPOLIAMIDA ASOCIADO A UN ELASTÓMERO TERMOPLÁSTICO EN LA TRÁQUEA DE UN CONEJO}

\section{RESUMEN}

La termografía es eficaz para detectar la temperatura de la superficie corporal y puede utilizarse como método auxiliar para diagnosticar procesos inflamatorios y para evaluar patrones de cicatrización, lo que permite su amplio uso en Medicina Veterinaria. El procedimiento ha ganado protagonismo por ser una técnica no invasiva, indolora, de bajo costo y segura, ya que elimina la necesidad del uso de contrastes, sedación y radiación. El objetivo de este artículo es analizar la eficacia del uso de la termografía en la evaluación de la biocompatibilidad en la reparación del tejido traqueal, así como identificar procesos inflamatorios tras la implantación de la prótesis impresa en nailon con impresión 3D asociada al elastómero termoplástico - PCTPE. Se dividieron quince conejos blancos de Nueva Zelanda (Oryctolagus cuniculus) machos en tres grupos de diferentes períodos de evaluación (siete, 15 y 30 días). Se implantaron prótesis tridimensionales tras la resección completa de tres anillos traqueales. La evaluación de las imágenes termográficas se realizó en el lugar de implantación de la prótesis traqueal justo antes del procedimiento quirúrgico e inmediatamente antes de la eutanasia. Hubo una diferencia significativa entre los grupos, ya 
los 30 días la temperatura mínima $(\mathrm{p}=0,0357)$, media $(\mathrm{p}=0,0135)$ y máxima $(\mathrm{p}=0,0058)$ fue menor en comparación con los otros grupos. Esto se justifica por el hecho de que este grupo encaja en la fase de maduración de la reparación de heridas, donde no hay más inflamación ni formación de tejido de granulación, lo que provoca que las temperaturas asuman valores más bajos. Se concluyó que la técnica fue eficaz para detectar patrones inflamatorios y cicatrizantes.

Palabras-llave: biopolímeros; Impresión 3d; prótesis; reconstrucción traqueal; termografía.

\section{INTRODUÇÃO}

Com o avanço da tecnologia e o interesse no aprimoramento dos resultados diagnósticos, a termografia tem ganhado destaque, pois trata-se de técnica não invasiva, indolor, de baixo custo e segura, uma vez que não traz riscos à saúde por dispensar a necessidade do uso de contrastes, sedação e radiação (1). A técnica permite identificar processos inflamatórios, uma vez que o calor é um dos principais sinais de inflamação e surge antes mesmo de qualquer outro sinal clínico (2). É um método de representação gráfica das temperaturas, em que é possível fazer a detecção dos padrões térmicos que são produzidos por emissão infravermelha de calor da superfície corporal (3).

A radiação infravermelha é captada por termógrafos, que são instrumentos capazes de identificar pequenas variações térmicas, pela alta sensibilidade e resolução (4). Depois disso, são formadas imagens térmicas com diferentes distribuições de temperatura, denominadas termogramas (5).

Para a obtenção de imagens térmicas, é feita análise de dados do software do termograma, que possibilita a leitura de imagens, avaliação, obtenção de resultados, além de conseguir detectar alterações a partir de $0,05^{\circ} \mathrm{C}$, enquanto, ao toque humano, essa percepção não é possível com menos de $2^{\circ} \mathrm{C}$ de variação. Dessa forma, é importante salientar a relevância do uso dessa técnica na medicina veterinária, agregando e tornando possível a maior acurácia no diagnóstico, uma vez que apresenta grande sensibilidade e alta resolução (6).

Um biomaterial pode ser uma substância ou uma associação de substâncias que podem ser empregadas por um período de tempo indefinido, com o intuito de tratar, aumentar ou substituir um tecido, órgão ou função do corpo (7).

Associada às evoluções na área médica, a tecnologia da impressão $3 \mathrm{D}$ está sendo empregada em escala de produção de implantes, próteses, engenharia do tecido esquelético e modelos anatômicos baseados em imagem (8).

Em virtude da eficiência de confeccionar objetos em dimensões tridimensionais a partir de um modelo digital, os biopolímeros impressos 3D, têm ganhado cada vez mais importância e aplicabilidade na engenharia de tecidos e, por receber atenção expressiva, desenvolveram-se vários projetos de pesquisa em relação aos sistemas disponíveis para a impressão 3D (9).

Uma vez que a prótese traqueal impressa tridimensionalmente já foi descrita na medicina e mostra efeitos futuros e satisfatórios (10-13), o advento de próteses aprimoradas vem despertando vários estudos nessa linha de pesquisa $(14,15)$.

Com este trabalho, objetivou-se analisar a eficiência do uso da técnica de termografia na avaliação da biocompatibilidade na reparação tecidual traqueal, após a implantação da prótese de nylon associada ao elastômero termoplástico confeccionada por impressão 3D em coelhos, bem como avaliar as mudanças de padrões térmicos e se a referida técnica pode auxiliar no 
diagnóstico de processos inflamatórios e na reparação tecidual após a implantação desse biomaterial.

\section{MATERIAIS E MÉTODOS}

Ética: Este estudo foi aprovado pela Comissão de Ética no Uso de Animais (CEUA) da Universidade Estadual Paulista (UNESP), Câmpus de Jaboticabal (Protocolo número 00798917).

Animais e grupos: Foram utilizados 15 coelhos machos, da linhagem Nova Zelândia Branco (Oryctolagus cuniculus), aleatorizados por sorteio e distribuídos em três grupos, sendo eles: Grupo Prótese sete dias (GP 7d- n=5, eutanásia aos 7 dias), Grupo Prótese quinze dias (GP 15d- n=5, eutanásia aos 15 dias) e Grupo Prótese trinta dias (GP 30d- n=5, eutanásia aos 30 dias).

Prótese 3D: As próteses foram projetadas em programa computacional de prototipagem tridimensional Solidworks 2016. O arquivo foi convertido em formato STL (stereolithography format) e impresso no método de modelagem por fusão e deposição em impressora da marca Prusa, modelo I3. O material utilizado para a confecção das próteses foi o náilon associado a elastômero termoplástico - PCTPE (Figura 1A). As dimensões foram baseadas na média das mensurações prévia da porção média traqueal de cadáveres de coelhos. Foram embaladas em papel grau cirúrgico e autoclavadas de ciclo rápido em 121 graus celsius por 15 minutos.

Procedimentos: O protocolo anestésico consistiu em medicação pré-anestésica outilizando cloridrato de clorpromazina na dose de $0,5 \mathrm{mg} / \mathrm{kg}$, e morfina, na dose de $0,5 \mathrm{mg} / \mathrm{kg}$, diluídos na mesma seringa, por via intramuscular (im). Em seguida, foi realizada tricotomia ampla da região das orelhas para o acesso venoso. A indução anestésica foi conduzida com o uso de propofol, na dose de $10 \mathrm{mg} / \mathrm{kg}$, seguida de intubação orotraqueal com sonda de Magill de 2,5 mm de diâmetro sem cuff, conectada ao aparelho de anestesia para fornecimento fluxo total de $1 \mathrm{~L} / \mathrm{min}$ de oxigênio a $100 \%$ por meio de circuito anestésico avalvular. Foi instituída anestesia geral inalatória com isofluorano, na dose de $3 \%$, diluído em $100 \%$ oxigênio. A cirurgia teve início com anti-sepsia prévia e definitiva da região cervical com clorexidine degermante e alcoólico, com posterior colocação de campos estéreis. Foi realizada incisão de pele, longitudinal e afastamento da musculatura e fáscias locais, desde a cartilagem cricoide até o manúbrio, com posterior dissecção da traqueia, preservando-se sua porção lateral, responsável pela vascularização. Foi realizada ressecção total em 360 graus da traqueia na altura do $5^{\circ}$ anel traqueal até o $8^{\circ}$ anel, gerando o defeito. $\mathrm{O}$ implante de PCTPE foi ajustado no interior do lúmen dos segmentos, e suturado com quatro pontos cardeais de reparo nas extremidades da prótese, utilizando-se nylon 3-0 agulhado (Figura 1B). Após o término da sutura simples isolado, foi criado retalho muscular com o músculo esternocefálico que serviu para se acomodar sobre a junção traqueia/prótese, a fim de auxiliar na cicatrização e evitar estravasamento de ar, os músculos esternohióideos e esternotireoídeos foram aproximados por sutura contínua com fio de nylon 3-0 agulhado.

Avaliação clínica: os animais foram observados diariamente para avaliação do padrão respiratório e identificação de qualquer alteração que pudesse ser atribuída ao procedimento cirúrgico, tais como: apneia, dispneia, enfisema subcutâneo, respiração ruidosa ou sibilante, aumento de volume no local de ferida cirurgica e presença de secreções.

Eutanásia: foram submetidos à administração, por via intravenosa, de propofol (doseresposta) e, ao certificar-se da ausência de reflexos corneal e pupilar, foi realizada a aplicação de $20 \mathrm{~mL}$ de cloreto de potássio por via intravenosa para a indução de assistolia.

Avaliação por câmera termográfica: Para a execução das imagens termográficas, a câmera utilizada foi da marca FLIR $^{\circledR}$ T-300, ajustada para focalização a $30 \mathrm{~cm}$ de distância 
com regulagem automática do foco. $\mathrm{O}$ equipamento possui sensibilidade térmica de 0.05 graus e resolução IR de 320x240 (76800 pixels), além de captar uma faixa de temperatura que varia de -20 a 650 graus Celsius. A avaliação termográfica da região traqueal foi realizada imediatamente após a indução anestésica para o procedimento cirúrgico e antes de cada momento de eutanásia.

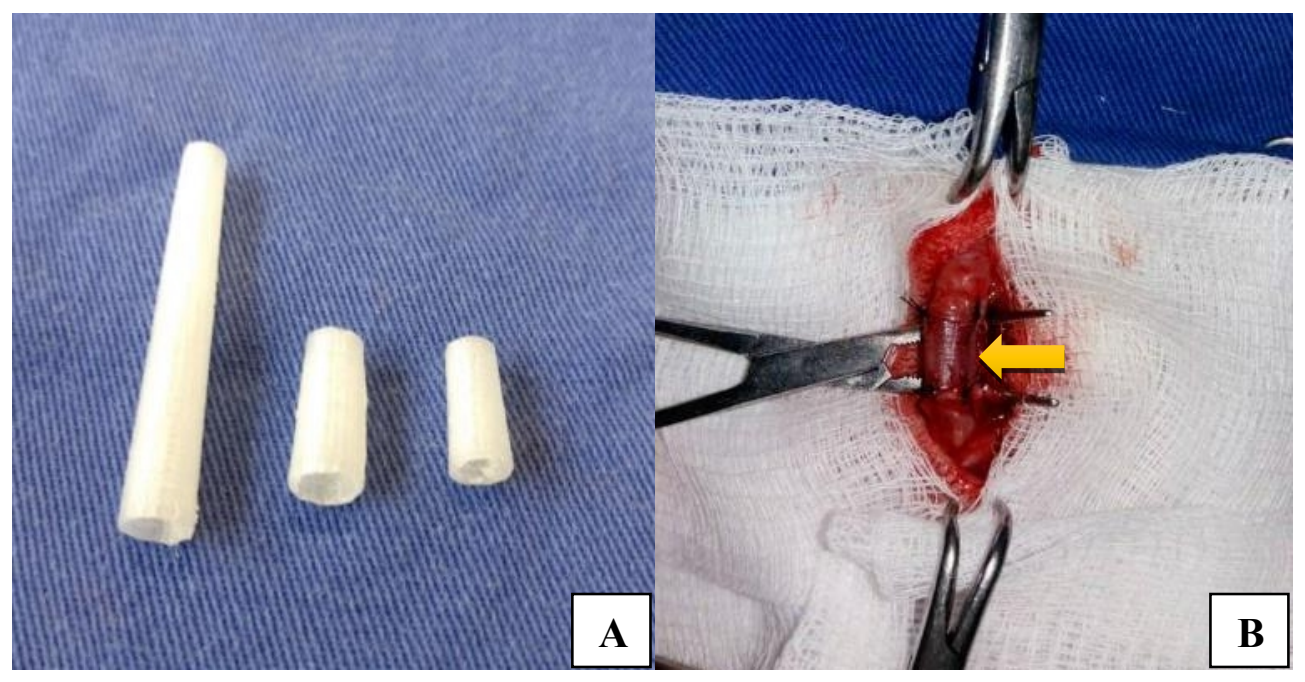

Figura 1. (A) Próteses traqueais confeccionadas em impressora em 3D com nylon associado a elastômero termoplástico - PCTPE. (B) Após a ressecção de três anéis traqueais, foi feita anastomose da prótese com os anéis traqueais adjacentes (seta amarela). Setor de Cirurgia Geral e Endoscopia Veterinária (CIGEV) da Faculdade de Ciências Agrárias e Veterinárias - FCAV/UNESP, Jaboticabal,SP, 2018.

Análise estatística. O software utlizado foi o SAS (version 9.3, SAS Institute, Cary, NC, USA). Os dados obtidos foram submetidos à análise de variância pelo procedimento GLM e a comparação das médias, pelo método de Tuckey. $O$ grau de significância estabelecido para o teste estatístico foi de $5 \%(p<0,05)$.

\section{RESULTADOS}

As cirurgias foram realizadas nos 15 animais sem qualquer intercorrência. Não ocorreram óbitos durante os procedimentos, nem complicações que pudessem ser atribuídas ao implante ou à técnica. Até o momento da eutanásia, nenhum animal dos três grupos que compunham o presente trabalho apresentou sinais como apneia, dispneia, enfisema subcutâneo, respiração ruidosa ou sibilante, demonstrando, assim, padrões respiratórios dentro da normalidade. Além disso, nenhum dos animais apresentou aumento de volume no local de ferida cirurgica ou presença de secreção.

A diferença nos valores de temperatura obtidas no momento pré-operatório e pré eutanásia do GP 7d, mostrou que apenas um animal apresentou acréscimo na temperatura mínima enquanto outro animal mostrou uma diminuição da temperatura média. Ao se tratar da temperatura máxima, dentro do mesmo grupo, todos os animais apresentaram aumentos em seu valor.

Já no GP 15d, ao compararem-se os valores de temperatura entre os momentos précirúrgico e pré eutanásia, foi observado que três animais apresentaram queda na temperatura mínima, enquanto todos os outros apresentaram acréscimos nas temperaturas máximas e médias. 
Por fim, no GP 30d, ao compararem-se os mesmos momentos, foi visto que dois animais apresentaram aumentos nas temperaturas mínimas e dois apresentaram decréscimos na temperatura máxima. Ainda, todos os animais do grupo apresentaram aumento em suas temperaturas máximas.

Conforme avaliado na análise estatística, verificou-se diferença significativa entre os grupos, sendo que, aos trinta dias, a temperatura mínima $(p=0,0357)$, média $(p=00135)$ e máxima $(p=0,0058)$ foi menor no GP $30 \mathrm{~d}$ quando comparadas com os demais grupos.

A tabela a seguir, demonstra os resultados adquiridos pela análise estatística que foi realizada com a ajuda do software SAS (version 9.3, SAS Institute, Cary, NC, USA) através do Teste de Tuckey. O grau de significância estabelecido para o teste estatístico foi de 5\% $(\mathrm{p}<0,05)$ (Tabela 1).

Em relação à temperatura mínima, todos os grupos diferiram estatisticamente do GP 30d. Houve diferença significativa de temperaturas máximas no momento pré eutanásia entre os três grupos. O GP 30d mostrou temperaturas mais baixas nesse momento, enquanto os demais grupos apresentaram temperaturas mais altas, no mesmo momento, devido à inflamação local que ainda estava presente.

Houve diferença estatística significativa entre as temperaturas médias, no momento pré eutanásia, entre o GP 15d e GP 30d. Isso indica que as temperaturas com 15 e 30 dias de cicatrização são diferentes, evidenciando que, aos 15 dias de pós-operatório, a temperatura tende a estar elevada devido ao processo de cicatrização que está ocorrendo no leito da ferida, e, aos 30 dias, a temperatura reduz devido à integridade da ferida cirúrgica e ausência de sinais de inflamação, com cicatrização do foco cirúrgico.

As imagens térmicas são representadas por um mapa de cores, onde as regiões mais quentes são brancas ou vermelhas, relacionadas à inflamação, em que se tem aumento de taxa metabólica e circulação local $(16,17)$. Já os locais mais frios são representados em azul ou preto, relacionados a processos onde se tem diminuição de perfusão tecidual, infarto, edema, fibrose ou atrofia muscular (16-18) (Figura 2).

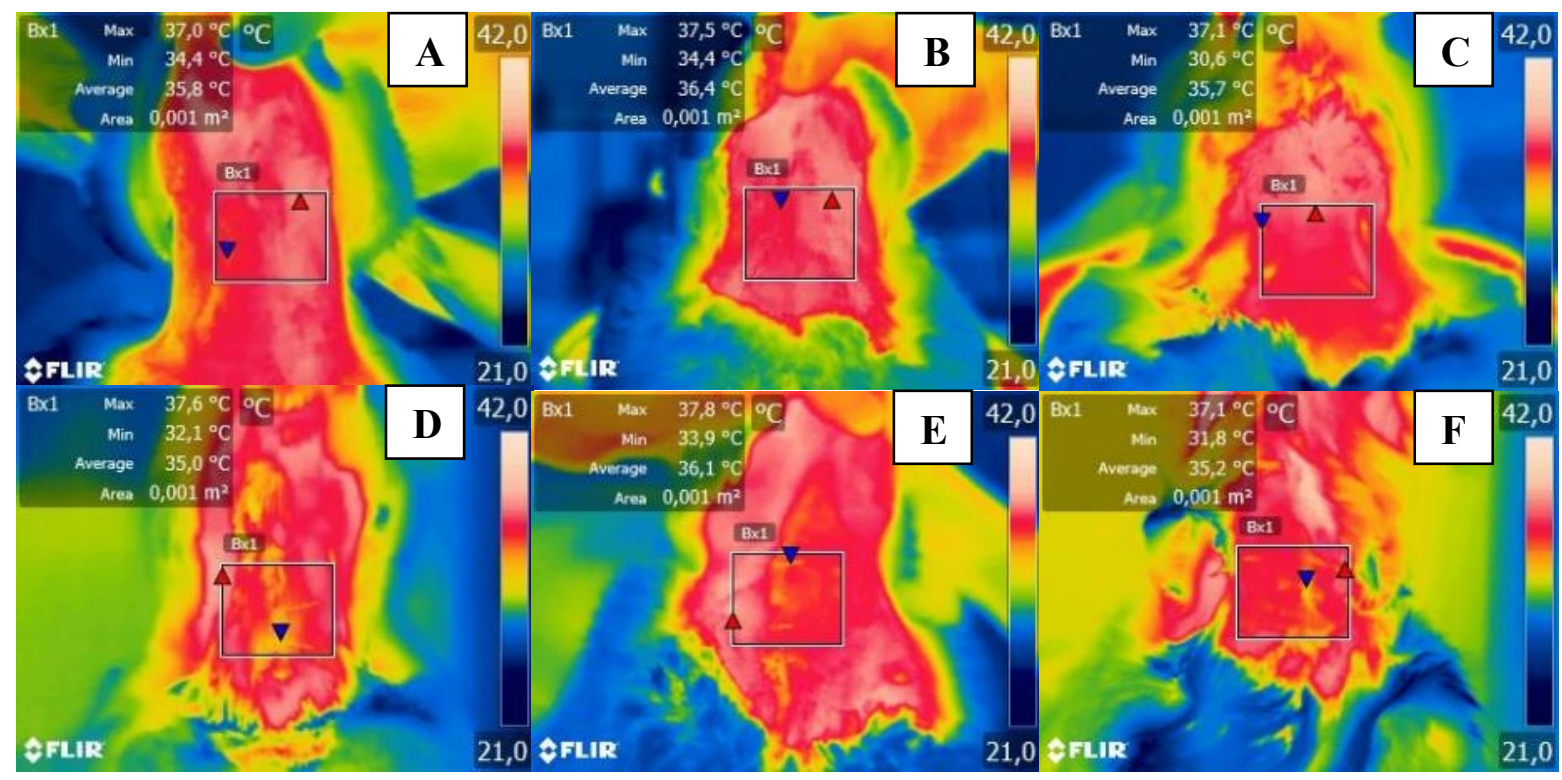

Figura 2. Sequência de imagens termográficas obtidas durante o presente trabalho, onde as áreas mais quentes são representadas em branco ou vermelho e as mais frias, em azul ou preto. Os quadrados presentes nas imagens, representam o local de implantação da prótese traqueal. As flechas vermelhas indicam o ponto mais quente da área em estudo, já as flechas azuis, os pontos mais frios. A) Animal do GP 7 dias, pré-cirúrgico. B) Animal do GP 15 dias, pré-cirúrgico. C) Animal do GP 30 
dias, pré-cirúrgico. D) Animal do GP 7 dias, pré-eutanásia. E) Animal do GP 15 dias, pré-eutanásia. F) Animal do GP 30 dias, pré-eutanásia. Setor de Cirurgia Geral e Endoscopia Veterinária (CIGEV) da Faculdade de Ciências Agrárias e Veterinárias - FCAV/UNESP, Jaboticabal,SP, 2018.

\section{DISCUSSÃO}

O presente trabalho teve como objetivo principal avaliar, em coelhos, por termografia, a área de implante de próteses de PCTPE manufaturadas em impressão 3D após ressecção de três anéis traqueais. Com avaliação termográfica pode-se aferir a temperatura do leito cirúrgico, comparando assim o processo inflamatório local, uma vez que um dos principais sinais de inflamação é o aumento de temperatura local. Pelas análises seriadas, constatou-se que não houve grande aumento de temperatura local ao longo dos tempos de análises termográficas, demonstrando, assim, que a prótese não induziu a um processo inflamatório exacerbado. Pela termografia, é possível, facilmente, acompanhar a inflamação local, visto que o exame não é invasivo e não gera estresse aos pacientes, além de ser de rápida execução.

Processos de quebra da homeostase podem ser indicados por variações na temperatura, uma vez que o calor da pele é baseado na circulação local (19). Portanto, a termografia é ferramenta capaz de salientar afecções com quaisquer tipos de alteração de perfusão sanguínea, como inflamações, fibroses, processos tumorais, neuropatias ou isquemias (20). Nesse estudo, o emprego da prótese traqueal sintética produzida por impressora tridimensional, poderia ter sido uma causa da quebra da homeostase, pois nesse processo houve a substituição de um tecido natural por um material sintético em que, possivelmente, poderia incitar complicações como inflamação, fibrose e isquemia, o que causaria alterações térmicas locais. Porém, não houve qualquer dessas complicações, sendo seu uso favorável em traqueoplastias.

A associação entre o tecido receptor e o implante de biomateral foi avaliada pela técnica de termografia e mostrou que houve diferença significativa entre os grupos avaliados de acordo com os dias pós cirúrgicos. Aos 30 dias, as temperaturas captadas foram menores no grupo 30 dias quando comparado com os demais grupos. Isso se deve ao fato de que, segundo Mandelbaum et al. (21), o processo inflamatório é consequente de atividade de vários mediadores químicos, além das células inflamatórias, como os leucócitos polimorfonucleares (PMN), macrófagos e linfócitos. Os leucócitos polimorfonucleares (PMN) iniciam sua atividade logo após a lesão tecidual e permanecem por três a cinco dias, sendo responsáveis pela fagocitose de bactérias. Já os macrófagos ficam ativos no local da lesão do terceiro ao décimo dia, fagocitando bactérias, desbridando corpos estranhos e ordenando a evolução do tecido de granulação. Por outro lado, os linfócitos começam a atuar em aproximadamente uma semana. Tal fato, contribuiu para que as temperaturas nos grupos 7 e 15 dias apresentassem-se mais elevadas.

A cicatrização de feridas constitui uma perfeita e coordenada cascata de eventos que ocorrem em níveis celulares e moleculares, com a finalidade de promover a reconstrução do tecido lesado (22). Esse processo de reparo tecidual é subdividido em fases com limite não muito definidos, sendo elas: hemostasia; fase inflamatória; formação do tecido de granulação, com deposição de matriz extracelular (colágeno, elastina e fibras reticulares); e remodelação (23-26).

A fase inflamatória inicia-se no momento em que ocorre a lesão. Isso ocorre, pois, o sangramento promove o transporte de plaquetas, hemácias e fibrina. Com a lesão tecidual, tem-se a liberação local de histamina, serotonina e bradicinina provocando alguns dos sinais inflamatórios, como calor e rubor. Isso acontece devido à vasodilatação e aumento de fluxo sanguíneo no local. A resposta inflamatória, que dura cerca de três dias, é a fase em que 
ocorre a migração sequencial das células para a ferida sendo que os primeiros elementos celulares a alcançarem o local são os neutrófilos e os monócitos. $\mathrm{O}$ pico de atividade dos polimorfonucleares ocorre nas primeiras 24-48 horas após o trauma (27). Nos dias iniciais de cicatrização, é esperado aumento da temperatura no leito da ferida devido aos mediadores inflamatórios que são responsáveis pelos sinais cardinais da inflamação; sendo assim, os resultados encontrados neste estudo são condizentes com a literatura, visto que a cicatrização interfere diretamente na temperatura do leito da ferida e, assim, pode-se inferir a importância do uso da termografia em pós cirúrgicos para avaliar o andamento da cicatrização. Os animais do GP 7d apresentaram graus acentuados de inflamação quando submetidos à avaliação microscópica, sendo detectados também pela técnica de termografia no presente trabalho (28).

A fase proliferativa é quando ocorre a formação de tecido de granulação, que é composto por um leito capilar, fibroblastos, macrófagos, um frouxo arranjo de colágeno, fibronectina e ácido hialurônico. Esta fase tem início por volta do $3^{\circ}$ dia após a lesão, permanecendo por 2 a 3 semanas, sendo o marco inicial da formação da cicatriz (27). O GP $15 \mathrm{~d}$ corresponde à fase proliferativa, apresentando as maiores médias de temperatura captadas pela técnica de termografia. Conforme os resultados da avaliação microscópica, os animais do GP 15d apresentaram, em sua maioria, graus discretos e moderados de hemorragia traqueal além de quatro animais apresentarem graus acentuados de inflamação (28). Ainda, três animais desse mesmo grupo, retrataram graus acentuados de congestão vascular traqueal e edema celular ou intersticial, o que explica as altas temperaturas captadas pela técnica de termografia, que se mostrou método muito eficiente.

Por fim, a fase de maturação da ferida, tem início durante a $3^{\mathrm{a}}$ semana momento em que há um aumento da resistência, sem aumento na quantidade de colágeno. Nesse período, a produção e destruição de fibras de colágenos, então em equilíbrio, graças à ação da colagenase. A fase de maturação dura toda a vida da ferida, sendo a taxa de maturação mais intensa durante as primeiras seis a oito semanas (27). Sendo assim, o GP 30d se enquadra na fase de maturação da ferida, onde não há mais inflamação ou formação de tecido de granulação, o que faz com que as temperaturas assumam valores mais baixos. Isso ficou evidente no presente artigo sendo que, aos 30 dias, a temperatura mínima, média e máxima foi menor no GP 30d quando comparado com os demais grupos. Tal fato pode ser justificado em razão de que, aos 30 dias de cicatrização, o leito da ferida cirúrgica estava íntegro e com as bordas do defeito já coaptadas. Os animais do GP 30d apresentaram recobrimento tecidual e grau de aderência acentuados, além de sinais de inflamação ausentes e graus moderados e acentuados de fibrose em região de prótese e anastomose na maioria dos animais que compunham o grupo (28). Portanto, no GP 30d, notou-se maior quantidade de tecido fibroso e formação de novos capilares para deposição de tecido conjuntivo, o que justifica as temperaturas mais baixas, captadas pelas imagens termográficas.

\section{CONCLUSÃO}

Conclui-se, com o presente trabalho, que a termografia pode ser utilizada como método auxiliar de diagnóstico de processos inflamatórios e cicatriciais, devido à eficiência na detecção da temperatura na superfície corporal, o que permite sua ampla utilização na Medicina veterinária.

Em relação à prótese traqueal de (PCTPE) impressa em 3D, ficou evidente que a mesma possui biocompatibilidade e função anatômica, uma vez que os animais não apresentaram reações inflamatórias exacerbadas, presença de secreções, padrões respiratórios anormais e óbitos, podendo, então, ser uma alternativa para o reparo de defeitos traqueais de grandes extensões.

Bini IFB, Yamashiro LM, Ido CK, Ribeiro JO, Montanhim GL, Pazzini JM, et al. Avaliação por câmera termográfica de implante de co-poliamida associado a elastômero termoplástico em traqueia de coelho. Vet. e Zootec. 2021; v28: 001-011. 


\section{REFERÊNCIAS}

1. Côrte ACR, Hernandez AJ. Termografia médica infravermelha aplicada à medicina do esporte. Rev Bras Med Esporte [Internet $\neg$ ]. 2016 [citado 20 Mar 2021] 22(4):315-9. doi: http://dx.doi.org/10.1590/1517-869220162204160783. Disponível em: http://www.scielo.br/scielo.php?script=sci_arttext\&pid=S1517$86922016000400315 \& \operatorname{lng}=$ en

2. Roberto JVB, Souza BB. Utilização da termografia de infravermelho na medicina veterinária e na produção animal. J Anim Behav Biometeorol. 2014;(2):73-84. doi: 10.14269/2318-1265/jabb.v2n3p73-84.

3. Infernuso T, Loughin CA, Marino DJ, Umbaugh SE, Solt OS. Thermal imaging of normal and cranial cruciate ligament-deficient stifles in dogs. Vet Surg. 2010;39(4):410-7. doi: https://doi.org/10.1111/j.1532-950X.2010.00677.x.

4. Figueiredo T, Dzyekanshi B, Kunz J, Silveira AB, Ramos CMG, Michelotto Júnior PV. A importância do exame termográfico na avaliação do aparato locomotor em equinos atletas. Rev Cient Eletronica Med Vet [Internet]. 2012 [citado 20 Mar 2021];9(18):1-15. Disponível em: http://faef.revista.inf.br/imagens_arquivos/arquivos_destaque/eLE4dfglj6RTrB2_2013 6-25-17-23-40.pdf

5. Ring EFJ. The discovery of infrared radiation in 1800. Imaging Sci J. 2000;48(1):1-8. doi: $10.1080 / 13682199.2000 .11784339$.

6. Davis J, Silva V. Subtração para detecção de pessoa em imagens térmicas. Rev Med Biol. 2004;23:79-88.

7. Pires ALR, Bierhalz ACK, Moraes AM. Biomateriais: tipos, aplicações e mercado. Quím Nova. 2015;38(7):957-71. doi: http://dx.doi.org/10.5935/0100-4042.20150094.

8. Wong J, Pfahnl A. 3D printing of surgical instruments for long-duration space missions. Aviat Space Environ Med. 2014;85(7):758-63. doi: https://doi.org/10.3357/ASEM.3898.2014.

9. Li X, Cui R, Sun LW, Aifantis KE, Fan Y, Feng QL, et al. 3D-printed biopolymers for tissue engineering application. Int J Polym Sci. 2014;2014:1-13. doi: https://doi.org/10.1155/2014/829145.

10. Chang JW, Park AS, Park JK, Choi JW, Kim YS, Shin YS, et al. Tissue-engineered tracheal reconstruction using three-dimensionally printed artificial tracheal graft: preliminary report. Artif Organs. 2014;38(6):95-105. doi: 10.1111 / aor.12310.

11. Park JH, Jung JW, Kang HW, Joo YH, Lee JS, Cho DW. Development of a 3D bellows tracheal graft: mechanical behavior analysis, fabrication and an in vivo feasibility study. Biofabrication. 2012;4(3):1-10. doi: https://doi.org/10.1088/1758-5082/4/3/035004.

12. Goldstein TA, Smith BD, Zeltsman D, Grande D, Smith LP. Introducing a 3dimensionally printed, tissueengineered graft for airway reconstruction: a pilot study.

Bini IFB, Yamashiro LM, Ido CK, Ribeiro JO, Montanhim GL, Pazzini JM, et al. Avaliação por câmera termográfica de implante de co-poliamida associado a elastômero termoplástico em traqueia de coelho. Vet. e Zootec. 2021; v28: 001-011. 
Otolaryngol Head Neck Surg. 2015;153(6):1001-6. doi: https://doi.org/10.1177/0194599815605492.

13. Park JH, Hong JM, Ju YM, Jung JW, Kang HW, Lee SJ, et al. A novel tissue engineered trachea with a mechanical behavior similar to native trachea. Biomaterials. 2015;62:10615. doi: https://doi.org/10.1016/j.biomaterials.2015.05.008.

14. Ellis PR Jr., Harrington OB, Beall AC Jr., De Bakey ME. The use of heavy Marlex mesh for tracheal reconstruction following resection for malignancy. J Thorac Cardiovasc Surg. 1962;44(4):520-7. doi: https://doi.org/10.1016/S0022-5223(19)32944-7.

15. Pemberton AH, Narodick BG, Worman LW. Tracheoplasty by means of a periosteal pedicle graft. J Thorac Cardiovasc Surg. 1964;47:572-6. doi: https://doi.org/10.1016/S0022-5223(19)33555-X.

16. Infernuso T, Loughin CA, Marino DJ, Umbaugh SE, Solt PS. Thermal imaging of normal and cranial cruciate ligament-deficient stifles in dogs. Vet Surg. 2010;39(4):410-7. doi: $10.1111 /$ j.1532-950X.2010.00677.x.

17. Marino DJ, Loughin CA. Diagnostic imaging of the canine stifle: a review. Vet Surg. 2010;39(3):284-95. doi: $10.1111 /$ j.1532-950X.2010.00678.x.

18. Mikail S. Termografia: diagnóstico através da temperatura. Nosso Clínico. 2010;13(74):20-4.

19. Vianna DML, Carrive P. Changes in cutaneous and body temperature during and after conditioned fear to context in the rat. Eur J Neurosci. 2005;21(9):2505-12. doi: 10.1111/ j.1460-9568.2005.04073.x.

20. Brioschi ML, Macedo JF, Macedo CRA. Termografia cutânea: novos conceitos. Rev Vasc Bras. 2003;2(2):151-60.

21. Mandelbaum SH, Santis EPD, Mandelbaum MHS. Cicatrização: conceitos atuais e recursos auxiliares - Parte I. An Bras Dermatol. 2003;78(4):393-410. doi: https://doi.org/10.1590/S0365-05962003000400002.

22. Ortonne JP, Clévy JP. Physiologie de la cicatrisation cutanée. Rev Prat. 1994;44(13):1733-4.

23. Carrel A. The treatment of wounds. JAMA. 1910;55(25):2148-50. doi: 10.1001 / jama.1910.04330250044011.

24. Branski RC, Rosen CA, Verdolini K, Hebda PA. Biochemical markers associated with acute vocal fold wound healing: a rabbit model. J Voice. 2005;19(2):283-9. doi: https://doi.org/10.1016/j.jvoice.2004.04.003.

25. Shimizu T. Role of macrophage migration inhibitory factor (MIF) in the skin. J Dermatol Sci. 2005;37(2):65-73. doi: https://doi.org/10.1590/S1413-78522006000300007.

Bini IFB, Yamashiro LM, Ido CK, Ribeiro JO, Montanhim GL, Pazzini JM, et al. Avaliação por câmera termográfica de implante de co-poliamida associado a elastômero termoplástico em traqueia de coelho. Vet. e Zootec. 2021; v28: 001-011. 
26. Rocha Junior AM, Oliveira RG, Farias RE, Andrade LCF, Aerestrup FM. Modulação da proliferação fibroblástica e da resposta inflamatória pela terapia a laser de baixa intensidade no processo de reparo tecidual. An Bras Dermatol. 2006;81(2):150-6. doi: https://doi.org/10.1590/S0365-05962006000200006.

27. Tazima MFGS, Vicente YAMVA, Moriya T. Biologia da ferida e cicatrização. Medicina (Ribeirão Preto). 2008;41(3):259-64. doi: https://doi.org/10.11606/issn.21767262.v41i3p259-264.

28. Yamashiro LM. Biocompatibilidade de implante de co-poliamida associada à elastômero termoplástico (PCTPE) customizado por impressora tridimensional em anastomose traqueal de coelho (Oryctolagus cuniculus) [dissertação] [Internet]. Jaboticabal: Faculdade de Ciências Agrárias e Veterinárias, Universidade Estadual Paulista; 2019 [citado 20 Mar 2021]. Disponível em: https://repositorio.unesp.br/handle/11449/181759

Recebido em: 23/03/2021

Aceito em: 21/06/2021 